\title{
Another View on the Role of Photosynthetic Pigments in Taxonomy of Oxygenic-Phototrophic Bacteria: Proposed Rejection of the Order Prochlorales Florenzano, Balloni, and Materassi 1986 (Emend. Burger-Wiersma, Stal, and Mur 1989), the Family Prochloraceae Florenzano, Balloni, and Materassi 1986, and the Family Prochlorotrichaceae Burger-Wiersma, Stal, and Mur 1989
}

\author{
ALEXANDER V. PINEVICH, ${ }^{*}$ SVETLANA G. AVERINA, AND NATALIA V. VELICHKO \\ Laboratory of Microbiology, University of St Petersburg, Old Peterhof, 198904 St Petersburg, Russia
}

\begin{abstract}
We propose that the order Prochlorales Florenzano, Balloni, and Materassi 1986 (emend. Burger-Wiersma, Stal, and Mur 1989), the family Prochloraceae Florenzano, Balloni, and Materassi 1986, and the family Prochlorotrichaceae Burger-Wiersma, Stal, and Mur 1989, validly published in the International Journal of Systematic Bacteriology under the rules of the Bacteriological Code, be rejected because of the imperfection of ordinal diagnosis. The oxygenic-phototrophic prokaryotes involved are proposed to be incorporated under their validly published names into the orders Chroococcales and Oscillatoriales of the "Cyanobacteria" group. Correspondingly, the latter is proposed to be upgraded to equal "Oxygenic photosynthetic bacteria" (Section 19 in Bergey's Manual).
\end{abstract}

Oxygenic phototrophy is the generation of proton motive force due to light-driven transport of electrons which are extracted from water; a universal complement of the genomes in oxygenic phototrophs are the $p s a, p s b$, and wox gene assemblages (12). Oxygenic phototrophs are assigned to 1 of 11 major bacterial phyla, which has been convincingly demonstrated by the analysis of $16 \mathrm{~S}$ rRNA sequences (22). The diversity of oxygenic phototrophs comprises, beside the members of Section 19, "Oxygenic photosynthetic bacteria" (6), bacterium-derived cellular entities: cyanelles and plastids. The former are obligate endocytobionts in the glaucophyceans, whereas the latter are prokaryote partners-with eukaryotes as second partner-in the photosynthetic chimerae, which belong to the kingdoms Plantae, Chromista, and Protozoa (8).

Cyanobacteria are considered to be the principal group of oxygenic-phototrophic bacteria because of a broad spectrum of revealed objects and deep penetration into their structure and functions. A characteristic feature of cyanobacteria is the phycobilisome, the major light-harvesting complex (LHC) built of phycobiliprotein heterodimers which are interconnected with colorless polypeptide linkers. Phycobilisomes are anchored to the protoplasmic surface of the light energy-transducing membrane with a bilin chromophore-bearing polypeptide (1). Besides the cyanobacteria, oxygenic-phototrophic bacteria include a small assemblage of prochlorophytes which is hallmarked by a possession of the intramembranous, carotenoid chlorophyll (Chl) $a / b$-containing LHC instead of the "traditional" phycobilisome.

Oxygenic-phototrophic bacteria are not yet (if at all) classified in harmony with their evolutionary relationships, because the evaluation of phenotypic and genotypic similarities does not yield congruent results. Data by many authors who con-

\footnotetext{
* Corresponding author. Mailing address: Laboratory of Microbiology, University of St Petersburg, Oranienbaum Chaussee 2, Old Peterhof, 198904 St Petersburg, Russia.
}

tributed to the present knowledge about oxygenic-phototrophic phylogeny that includes the "prochloralian" genera (33) show that $16 \mathrm{~S}$ rRNA sequencing results do not support phenotype-based classification schemes. This conflict is not uncommon in prokaryotes (34), and since taxonomy operates with organisms rather than with genomes, the priority is conventionally given to essentials of the metabolism and/or cell architecture (21). Unfortunately, a classification based on physiological distinctions, which proves a success in major bacterial groupings, is unattainable in oxygenic-phototrophic bacteria because of a high level of uniformity of their metabolism. As a result, the taxonomy of cyanobacteria concentrates on the markers which have a bearing on cytology par excellence. The principles of botanical classification based on morphology only, together with bacteriological approaches (27), were introduced in the last version of Bergey's Manual (6). In terms of the higher taxons, cyanobacteria fall into subsections (orders) Chroococcales, Pleurocapsales, Oscillatoriales, Nostocales, and Stigonematales. The respective diagnoses are based on markers which are recognized at the organismic level, viz. growth in either unicells or trichomes, fission binary and/or multiple, differentiation under stress conditions absent or yielding the akinetetype dormant cells and heterocyst-type diazotrophocytes, or branching pattern of true or false (6). That (ultra)structural resemblance does not guarantee genetic relatedness and vice versa is illustrated by unicellular species which are scattered across the phylogenetic tree (33). At the same time, single mutations may suffice for a substitution of the unicell for a trichome (2).

Ralph Lewin's discovery of the prochlorophytes has been followed by a delayed understanding of their proximity to and necessity to relate their taxonomy to that of cyanobacteria (26, 33 ). It seemed logical to offer the accessory photosynthetic pigment as a top-grade phenotypic marker and, despite a close resemblance of the unicellular Prochloron didemni and filamentous Prochlorothrix hollandica to the chroococcalean and oscillatorian cyanobacteria, respectively $(18,26)$, the phycobil- 
iprotein - $\mathrm{Chl} b$ alternative has been recognized as a hallmark of the order Prochlorales, which opposes the cyanobacteria in general $(5,9)$.

In our opinion, this taxonomic proposal should be reconsidered, primarily because a virtual catalog of LHC pigments already substitutes for the phycobiliprotein - $\mathrm{Chl} b$ alternative, and it is possibly far from completion. Thus, divinyl-Chls $a$ and $b$ were discovered in Prochlorococcus marinus (7), whereas a $\mathrm{Chl} c$ - like pigment was reported in Prochloron didemni (15) and Prochlorococcus marinus (7). A phycobilisome-less symbiont of colonial ascidians, provisionally named Acaryochloris marina, has been recently shown to contain $\mathrm{Chl} d$ as a major pigment (20). An aggravating aspect is pigment combinations: $P$. marinus and $P$. didemni have both (divinyl) $\mathrm{Chl} b$ and a $\mathrm{Chl}$ $c$-like pigment $(7,15)$. In the anonymous marine oxygenicphototrophic bacterium, $\mathrm{Chl} b$ coexists with phycoerythrin (13), whereas a small amount of a $\mathrm{Chl} b$-like pigment is present in the phycoerythrin-rich freshwater cyanobacterium Synechococcus sp. (25). A. marina contains Chl $a$ in a 0.027 to 0.092 ratio to $\mathrm{Chl} d(20)$. Based on the consistently applied pigment criterion by Florenzano et al. (9), one would be forced to propose ordinal-rank taxons every time a new pigment or combination of pigments is demonstrated.

The second reason for the order Prochlorales being rejected is that taxonomic manipulations with LHC pigments are misleading from a conceptual viewpoint. Actually, the indication of a pigment alone sheds no light on LHC organization, which is rather determined by the primary structure of the apoprotein, the positions of chromophore-binding amino acid residues, the tertiary structure and hydropathy pattern of the polypeptide chain, the spatial architecture of higher aggregates of LHC modules, the association of LHC with a distinct membrane structure, and the LHC orientation with respect to the cytoplasm. It is generally agreed that a basis of the LHCs is the highly conserved sequences of apoprotein moiety (12). In a special case of oxygenic phototrophs these apoproteins are mutually related, and there is a homology within two heterologous groups: Chl-binding (hydrophobic, intrinsic) and bilinbinding (hydrophilic, extrinsic) polypeptides, respectively. On the whole, there are seven LHC types. Their descriptions have been reported elsewhere $(12,32)$, and only crucial aspects, including those of the occurrence and evolution, are highlighted below in the form of a necessary minireview.

An LHC with a Chl $a$-binding apoprotein (type i) represents a primordial type of the major light-harvesting antenna which is hypothesized to have persisted in cryptic oxygenic-phototrophic bacteria. An ability to exclusively depend on Chl $a$-LHC has been substantiated by the isolation of cyanobacterial mutants which are either devoid of phycobilisomes and detectable phycobiliproteins (4) or possess phycobiliproteins without antennal function (30).

LHCs with $\mathrm{Chl} a / b$-binding ( $\mathrm{Cab})$ apoproteins (type ii) are indicative of chloroplasts: plastids of the chlorophyceans, euglenophyceans, and terrestrial plants (23).

The evolutionary progenitor of $\mathrm{Cab}$ apoproteins are inducible Chl $a$-binding proteins (HLIPs) of cyanobacteria (19). Apart from plastids, the polypeptides with binding sites for Chls $a$ and $b$ are present in prochlorophytes; they demonstrate limited homology to the members of the Cab family (26). The study of evolutionary relationships of $\mathrm{Chl} a / b$-binding proteins in $P$. marinus, $P$. didemni, and $P$. hollandica has revealed their proximity to $\mathrm{CP} 43^{1}$, which is an iron stress-induced antennal protein of cyanobacteria $(16,31)$.

LHC with a Chl $a / b / c$-binding apoprotein (type iii) is characteristic of the plastids in the prasinophycean alga Mantoniella squamata (32). The alignment of amino acid sequences reveals a phylogenetic relationship of this apoprotein to Chl $a / b$-binding polypeptides (29). One has to remember that in accordance with recent evidence, $P$. marinus and $P$. didemni contain a $\mathrm{Chl}$ $c$-like pigment together with (divinyl) Chls $a$ and $b(7,15)$. Research with the respective apoprotein(s), especially sequence alignment to the $\mathrm{Chl} a / b / c$-protein of $M$. squamata, would explain the molecular evolution of this LHC.

An LHC with xanthophyll $\mathrm{Chl} a / c$-binding apoproteins, or the xanthosome (type iv), is a major light-harvesting antenna protein in the marine chromophycean algae and dinoflagellates $(11,12,14)$. Their relationship with $\mathrm{Chl} a / b$-binding apoproteins is now being supported by an increasing body of sequencing data (23). Xanthosomes represent supramolecular assemblies nearly $10 \mathrm{~nm}$ in diameter which are bound to thylakoid membranes (14). In bacteria, the occurrence of LHCs with only $\mathrm{Chl} c$ as an accessory $\mathrm{Chl}$ is still hypothetical (3).

An LHC with xanthophyll Chl $a$-binding apoproteins (type v) exists in the plastids of certain chrysophycean and eustigmatophycean algae (32). The apoproteins of this LHC are homologous to xanthophyll $\mathrm{Chl} a / c$-binding polypeptides (10). There are no data about a counterpart LHC in oxygenic-phototrophic bacteria.

An LHC with bilin chromophore-binding protoplasmic apoproteins, or the phycobilisome (type vi), is present in cyanobacteria, cyanellae, and rhodoplasts (plastids of red algae). They contain phycobiliproteins of three major groups (12) based on spectral properties (phycoerythrin, $A_{\max }=560 \mathrm{~nm}$; phycocyanin, $A_{\max }=625 \mathrm{~nm}$; and allophycocyanin, $A_{\max }=650 \mathrm{~nm}$ ). With an exception of the chroococcalean cyanobacterium Gloeobacter violaceus, which lacks intracytoplasmic membrane structures (28), phycobilisomes associate themselves with the protoplasmic (in the case of plastids, stromal) surface of thylakoids. The alignment of 100 phycobiliprotein subunits shows that they all have originated from a common ancestor polypeptide (1).

An LHC with bilin chromophore-binding exoplasmic apoproteins, or the quasiphycobilisome (type vii), differs from the phycobilisome in that it represents an unstructured assembly localized within the intrathylakoidal space. The only examples known are the plastids of the cryptophyceans (17). The apoproteins of this LHC are homologous to those in the cyanobacterial lineage (1).

Three of the LHC types described above have been never observed in bacteria. However, a monophyletic origin of plastids suggests that the same LHCs could have undergone mosaicism in the evolution of the photosynthetic apparatus of bacteria and organelles (3). It is reasonable, therefore, to expect future discoveries of missing bacterial counterparts of plastidal LHCs.

A special case is a photosynthetic apparatus with more than one type of LHC. Thus, in plastids of the cryptophyceans (17), the xanthosome (type iv) combines with quasiphycobilisome (type vii). At the same time, a coexistence of a Chl $a / b$-protein complex (type ii) with phycobilisome (type vi) is suggested in the newly isolated strains of oxygenic-phototrophic bacteria $(13,25)$. Theoretically, there is no restricted combination of the gene assemblages which code for different LHCs, and they may be constitutively or inducibly expressed. Because the number of total combinations of the seven LHCs by ones, twos, etc. is 127 , the presumptive orders of oxygenic-phototrophic bacteria outnumber by far those which result from the taxonomic proposal by Florenzano et al. (9).

As argued above, the bipartite (cyanobacteria and prochlorophytes), six-order (Chroococcales, Pleurocapsales, Oscillatoriales, Nostocales, Stigonematales, and Prochlorales) system of oxygenic-phototrophic bacteria degrades to a multiorder cata- 
$\log$ of LHC pigments and their combinations if it is confronted with the organisms outside of phycobiliprotein-Chl $b$ alternative. Unfortunately, the conceptually valid LHC approach is endangered by cataloging as well.

The third reason for the order Prochlorales being rejected is relevant to a long-lasting tradition of taking the taxonomic priority of LHC pigments or LH holocomplexes for granted (3), whereas in reality they are second-grade markers. In fact, the differences in LHCs do not correlate with those in the (ultra)structure and metabolism $(7,13,20)$. Not only LHCs, but also the pigment compositions of core antenna and even of reaction centers can vary; however, this does not affect the mechanism of oxygenic phototrophy, and no taxonomic application is an issue $(7,20)$. In this connection, one can refer to the taxonomy of other phototrophic bacteria: thus, in the phylogenetically coherent purple bacteria, possession of Bchl $b$, instead of Bchl $a$, has so far been considered insufficient for the discrimination between genera, whereas in the monophyletic filamentous green bacteria, LHCs may vary in different genera of the same family (24). In the case of oxygenic-phototrophic bacteria, the specificity of photosynthetic pigments and LHCs would only apply to genus criteria if it correlates with a specific cytology, e.g., with stacking of thylakoids (18) or with their absence (28).

In conclusion, recent progress in the study of cyanobacterial and "prochloralian" phylogeny (33) and photosynthetic apparates (18) makes it necessary to reconsider the current taxonomy. Our proposal is that oxygenic-phototrophic bacteria, irrespective of the type(s) of LHC and in accordance with the cytology-based ordinal diagnoses (6), be attributed to the orders Chroococcales, Pleurocapsales, Oscillatoriales, Nostocales, and Stigonematales within the group "Cyanobacteria." Correspondingly, we propose that the order Prochlorales Florenzano, Balloni, and Materassi 1986 (emend. Burger-Wiersma, Stal, and Mur 1989) be rejected. Simultaneously, the group "Cyanobacteria" is proposed to be upgraded to equal "Oxygenic photosynthetic bacteria" (Section 19 in Bergey's Manual). We also propose that the family Prochloraceae Florenzano, Balloni, and Materassi 1986 and the family Prochlorotrichaceae Burger-Wiersma, Stal, and Mur 1989 be rejected and that the prokaryotes validly described under the generic names Prochloron Lewin 1977 and Prochlorothrix Burger-Wiersma, Stal, and Mur 1989 be placed in the orders Chroococcales and Oscillatoriales, respectively. Although $16 \mathrm{~S}$ rRNA sequencing data do not support such a treatment (some filamentous cyanobacteria cluster with unicellular strains (33), our proposal agrees with a current taxonomy of bacteria which is, in its present state, principally phenotype based (21).

The validation of Chroococcales and Oscillatoriales, as well as future placement of cyanobacteria under the International Code of Nomenclature of Bacteria, are beyond the scope of this article. However, we hypothesize that a nonformal consensus between the botanical and bacteriological systems should be sought in morphological criteria only. Besides, the Bacteriological Code-based taxonomic treatment of new cyanobacteria can be easily performed in the case of original morphology, as it is exemplified by the genera Crinalium, Cyanospira, and Starria (6).

\section{REFERENCES}

1. Apt, K. E., J. L. Collier, and A. R. Grossman. 1995. Evolution of the phycobiliproteins. J. Mol. Biol. 248:79-96.

2. Bauer, C. C., W. J. Buikema, K. Black, and R. Haselkorn. 1995. A shortfilament mutant of Anabaena sp. strain PCC 7120 that fragments in nitrogendeficient medium. J. Bacteriol. 177:1520-1526.

3. Bhattacharya, D., and L. Medlin. 1995. The phylogeny of plastids: a review based on comparisons of small-subunit ribosomal RNA coding regions. J. Phycol. 31:489-498.
4. Bruce, D., S. Brimble, and D. A. Bryant. 1989. State transitions in a phycobilisome-less mutant of the cyanobacterium Synechococcus sp. PCC 7002. Biochim. Biophys. Acta 974:66-73.

5. Burger-Wiersma, T., L. J. Stahl, and L. R. Mur. 1989. Prochlorothrix hollandica gen. nov., sp. nov., a filamentous oxygenic photoautotrophic procaryote containing chlorophylls $a$ and $b$ : assignment to Prochlorotrichaceae fam. nov. and order Prochlorales Florenzano, Balloni, and Materassi 1986, with emendation of the ordinal description. Int. J. Syst. Bacteriol. 39:250257.

6. Castenholz, R. W., and J. B. Waterbury. 1989. Taxa of the cyanobacteria, p. 1727-1728. In J. T. Staley, M. P. Bryant, N. Pfennig, and J. G. Holt (ed.), Bergey's manual of systematic bacteriology, vol. 3. Williams \& Wilkins, Baltimore, $\mathrm{Md}$

7. Chisholm, S. W., S. L. Frankel, R. Goericke, R. J. Olson, B. Palenik, J. B. Waterbury, L. West-Johnsrud, and E. R. Zettler. 1992. Prochlorococcus marinus nov. gen. nov. sp.: an oxyphototrophic marine prokaryote containing divinyl chlorophyll $a$ and $b$. Arch. Microbiol. 157:297-300.

8. Corliss, J. O. 1994. An interim utilitarian ("user-friendly") hierarchical classification and characterization of the protists. Acta Protozool. 33:1-51.

9. Florenzano, G., W. Balloni, and R. Materassi. 1986. Nomenclature of Prochloron didemni (Lewin 1977) sp. nov., nom. rev., Prochloron (Lewin 1976) gen. nov., nom. rev., Prochloraceae fam. nov., Prochlorales ord. nov., nom. rev. in the class Photobacteria Gibbons and Murray 1978. Int. J. Syst. Bacteriol. 36:351-353.

10. Grevby, C., and C. Sundqvist. 1992. Characterization of light-harvesting complex in Ochromonas danica (Chrysophyceae). J. Plant Physiol. 140:414420 .

11. Grossman, A., A. Manodori, and D. Snyder. 1990. Light-harvesting proteins of diatoms: their relationship to the chlorophyll $a / b$ binding proteins of higher plants and their mode of transport into plastids. Mol. Gen. Genet. 224: $91-100$.

12. Grossman, A. R., D. Bhaya, K. E. Apt, and D. M. Kehoe. 1995. Lightharvesting complexes in oxygenic photosynthesis: diversity, control, and evolution. Annu. Rev. Genet. 29:231-288.

13. Hess, W. R., F. Partensky, G. W. M. van der Staay, J. M. Garcia-Fernandez, T. Börner, and D. Vaulot. 1996. Coexistence of phycoerythrin and a chlorophyll $a / b$ antenna in a marine prokaryote. Proc. Natl. Acad. Sci. USA 93: $11126-11130$.

14. Katoh, T., A. Tanaka, and M. Mimuro. 1993. Xanthosomes: supramolecular assemblies of xanthophyll-chlorophyll $a / c$ protein complexes. Methods Enzymol. 214:402-412.

15. Larkum, A. W. D., C. Scaramuzzi, G. C. Cox, R. G. Hiller, and A. G. Turner. 1994. Light-harvesting chlorophyll $c$-like pigment in Prochloron. Proc. Natl. Acad. Sci. USA 91:679-683.

16. La Roche, J., F. Partensky, and P. Falkovsky. 1995. The major light-harvesting antenna of Prochlorococcus marinus is similar to $\mathrm{CP}^{4} 3^{1}$, a Chl binding protein induced by iron limitation in cyanobacteria, p. 171-174. In P. Mathis (ed.), Photosynthesis: from light to biosphere, vol. I. Kluwer Academic Publishers, Dordrecht, The Netherlands.

17. Lichtlé, C., J. C. Duval, and Y. Lemoine. 1987. Comparative biochemical, functional, and ultrastructural studies of photosystem particles from a Cryptophycea: Cryptomonas rufescens: isolation of an active phycoerythrin particle. Biochim. Biophys. Acta 894:76-90.

18. Matthijs, H. C. P., G. W. M. van der Staay, and L. R. Mur. 1994. Prochlorophytes: the 'other' cyanobacteria? p. 49-64. In D. A. Bryant (ed.), The molecular biology of cyanobacteria. Kluwer Academic Publishers, Dordrecht, The Netherlands.

19. Miroshnichenko Dolganov, N. A., D. Bhaya, and A. R. Grossman. 1995. Cyanobacterial protein with similarity to the chlorophyll $a / b$ binding proteins of higher plants: evolution and regulation. Proc. Natl. Acad. Sci. USA 92: 636-640.

20. Miyashita, H., H. Ikemoto, N. Kurano, K. Adachi, M. Chihara, and S. Miyachi. 1996. Chlorophyll $d$ as a major pigment. Nature 383:402.

21. Murray, R. G. E., D. J. Brenner, R. R. Colwell, P. De Vos, M. Goodfellow, P. A. D. Grimont, N. Pfennig, E. Stackebrandt, and G. A. Zavarzin. 1990. Report of the ad hoc committee on approaches to taxonomy within the proteobacteria. Int. J. Syst. Bacteriol. 40:213-215.

22. Olsen, G. J., C. R. Woese, and R. Overbeek. 1994. The winds of (evolutionary) change: breathing new life into microbiology. J. Bacteriol. 176:1-6.

23. Paulsen, H. 1995. Chlorophyll $a / b$-binding proteins. Photochem. Photobiol. 62:367-382

24. Pfennig, N., and H. G. Trüper. 1989. Anoxygenic phototrophic bacteria, p. 1635-1637. In J. T. Staley, M. P. Bryant, N. Pfennig, and T. G. Holt (ed.), Bergey's manual of systematic bacteriology, vol. 3. Williams \& Wilkins, Baltimore, $\mathrm{Md}$.

25. Pinevich, A. V., H. C. P. Matthijs, S. G. Averina, and O. V. Gavrilova. Submitted for publication.

26. Post, A. F., and G. S. Bullerjahn. 1994. The photosynthetic machinery in prochlorophytes: structural properties and ecological significance. FEMS Microbiol. Rev. 13:393-413.

27. Rippka, R., J. Deruelles, J. B. Waterbury, M. Herdman, and R. Y. Stanier. 1979. Generic assignments, strain histories and properties of pure cultures of 
cyanobacteria. J. Gen. Microbiol. 111:1-61.

28. Rippka, R., J. Waterbury, and G. Cohen-Bazire. 1974. A cyanobacterium which lacks thylakoids. Arch. Microbiol. 100:419-436.

29. Schmitt, A., G. Frank, P. James, W. Staudenmann, H. Zuber, and C. Wilhelm. 1994. Polypeptide sequence of the chlorophyll $a / b / c$-binding protein of the prasinophycean alga Mantoniella squamata. Photosynth. Res. 40:269-277.

30. Shen, G., S. Boussiba, and W. F. J. Vermaas. 1993. Synechocystis sp. PCC 6803 strains lacking photosystem I and phycobilisome function. Plant Cell 5:1853-1863.

31. van der Staay, G. W. M., A. Ducret, R. Abersold, R. Li, S. S. Golden, R. G. Hiller, P. M. Wrench, A. W. D. Larkum, and B. R. Green. 1995. The Chl $a / b$ antenna from prochlorophytes is related to the iron stress-induced $\mathrm{Chl} a$ antenna (IsiA) from cyanobacteria, p. 175-178, In P. Mathis (ed.), Photosynthesis: from light to biosphere, vol. I. Kluwer Academic Publishers, Dordrecht, The Netherlands.

32. Wilhelm, C. 1990 . The biochemistry and physiology of light-harvesting processes in chlorophyll $b$ - and chlorophyll $c$ - containing algae. Plant Physiol. Biochem. 28:293-306.

33. Wilmotte, A. 1994. Molecular evolution and taxonomy of the cyanobacteria, p. 1-25, In D. A. Bryant (ed.), The molecular biology of cyanobacteria. Kluwer Academic Publishers, Dordrecht, The Netherlands.

34. Woese, C. R., O. Kandler, and M. L. Wheelis. 1990. Towards a natural system of organisms: proposal for the domains Archaea, Bacteria, and Eucarya. Proc. Natl. Acad. Sci. USA 87:4576-4579. 